\title{
Şarkılarla Değerler Eğitiminin Okul Öncesi Çocukların Farkındalık Düzeyine Etkisi
}

\section{The Impact of Values Education with Songs on the Awareness Level of Preschool Children}

\author{
Gülnihal GÜL, Sorumlu Yazar, Doç. Dr. \\ Uludağ Üniversitesi, Eğitim Fakültesi, Türkiye. \\ gulnihalgul@gmail.com \\ http:// orcid.org/0000-0001-9437-2419
}

Seda MINTAŞ, Öğretmen.

T.C. Milli Eğitim Bakanlığı, Türkiye.

mintasseda@gmail.com

http://orcid.org/0000-0003-3631-7889

Doruk ENGÜR, Dr. Öğr. Üyesi.

Bursa Uludağ Üniveritesi, Eğitim Fakültesi, Türkiye.

dorukengur@gmail.com

http:// orcid.org/0000-0002-1337-9828

\author{
ISSN: 1303-880X \\ e-ISSN: 2667-7504 \\ http://ded.dem.org.tr
}

Makale Türü / Article Type:

Araştırma Makalesi / Research Article

Geliş Tarihi / Received Date: 26.07.2019

Kabul Tarihi / Accepted Date: 24.12.2019

Yayın Tarihi / Published Date: 25.06.2020

Tr/En: $\operatorname{Tr}$

Intihal / Plagiarism: Bu makale, en az iki hakem tarafindan incelendi ve intihal içermediği teyit edildi. / This article has been reviewed by at least two referees and scanned via a plagiarism software.
Atıf/Citation: Gül, G., Mintaş, S. \& Engür, D. (2020). Şarkılarla değerler eğitiminin okul öncesi çocukların farkındalık düzeyine etkisi. Değerler Eğitimi Dergisi,18 (39), s.9-31. https://doi.org/10.34234/ded.597237 
Öz: Bu çalışmada, okul öncesi dönemde şarkılarla değerler eğitiminin çocukların farkındalık düzeyine etkisinin belirlenmesi amaçlanmıştır. Bu amaç doğrultusunda 2018-2019 eğitim/öğretim yılında Bursa'da yer alan, kolay ulaşılabilir örnekleme yöntemiyle seçilmiş bir okul öncesi kurumdaki çocuklardan oluşan çalışma grubuyla ön test - son test statik gruplu deneysel bir çalışma yürütülmüştür. Çalışma kapsamında önce değerler ve bu değerlere ilişkin şarkı dağarc1$\breve{g} 1$ belirlenmiştir. Değerlerin belirlenmesinde 3 alan uzmanına Okul Öncesi Eğitim Programında yer verilen değerleri içeren bir liste verilmiş ve uzmanlardan bu değerlerin öğretiminde kullanılabilecek şarkı önerileri istenmiştir. En çok önerilen dört değer ve bu değerlerin öğretilmesine uygun şarkılar çalışma kapsamına alınmıştır. Belirlenen değerlerle ilgili çocukların farkındalık düzeylerini tespit etmek amacıyla "Resimli Kartlar Testi" geliştirilmiş ve bu test ile deney ve kontrol gruplarının ön test puanları belirlenmiştir. Daha sonra belirlenen dağarcık ile 8 hafta boyunca deney grubuyla çalışılmış ve uygulama sonrasında iki gruba tekrar aynı test uygulanarak son test puanları belirlenmiştir. Ön test ve son test arasındaki değişime ilişkin olarak Wilcoxon işaretli sıralama testi ve gruplar arasındaki farkların belirlenmesinde Mann-Whitney U testi kullanılmıştır. Analizler sonucunda grupların arkadaşlık, güven ve yardımseverlik alt boyutları ile toplam puanlarındaki gelişmeleri arasında deney grubu lehine anlamlı fark $(\mathrm{p}<.05)$ olduğu belirlenmiştir.

Anahtar Kelimeler: Okul öncesi, Müzik eğitimi, Şark1, Değer.

$\&$

Abstract: The aim of this study is to determine the effect of values education with songs on the awareness level of preschool children. For this purpose, an experimental study was carried with a pre-test post-test static group designed out with children in a preschool institution selected by convenience sampling in Bursa in 2018-2019 academic year. Within the scope of the study, firstly the values and song repertoire related to these values were determined. A list of values incorporated into Preschool Education Program was given to 3 field experts and the song suggestions for teaching these values were requested. The four most recommended values and related songs were included in the study. The "Picture Cards Test" was developed to measure the awareness levels for the values, and the pre-test scores of both groups were determined via this test. Then, repertoire studied with the experimental group for 8 weeks and after the study process, the two groups were taken to the same test again and the post-test scores were determined. In the analysis, Wilcoxon signed rank, and Mann-Whitney U tests were employed. Results showed a significant difference ( $p$ 
$<.05$ ) between the development of friendship, trust and helpfulness sub-dimensions and total scores of the groups in favor of the experimental group.

Keywords: Preschool, Music education, Song, Value.

(The Extended Abstract is at the end of the article)

\section{Giriş}

Fiziksel, duygusal, sosyal ve zihinsel gelişimlerin en hızlı olduğu okul öncesi dönemde gerçekleştirilecek eğitim çocuğun kişilik gelişimini ve sonraki yıllardaki öğrenmesini de önemli ölçüde etkilemektedir (Gül, 2012, s. 3; Oktay, 2003, s. 25; Kuru Turaşl1, 2015, s.6). Bu nedenle okul öncesi dönemde gerçekleştirilecek eğitim çocuğun temel ihtiyaçlarını karşılayacak uygun öğrenme ortamlarında; çocuğun ilgi, ihtiyaç ve gelişim durumları göz önünde bulundurularak planlanmalıdır (Aral, 2006, s. 3; Aral, Kandır, \& Yaşar, 2000, s. 15; Kaya, Günay, \& Aydın, 2016, s. 24; Kantarc1, 2014, s.2).

Çocuğun bedensel, zihinsel, sosyal-duygusal, dil ve bilişsel gelişimlerini destekleyen, olumlu bir kişilik geliştirmesinde, tutum, davranış, inanç ve değer yargılarının oluşması-yerleşmesinde etkili bir süreç olarak düşünülen okul öncesi eğitim yolu ile çocuk öncelikle içinde bulunduğu kültürün değerlerine esneklik ve süreklilik kazanmakta daha sonra da çağın gereklerine uygun yeni değerler üretmektedir (Erbay, 2008, s. 7; Zembat, 2005, s. 27; Gürkan, 2016, s.31). Değerler, bireye etkili ve sağlıklı olarak kazandırılması toplumsal bütünlük ve huzurun sürdürülebilmesi ve toplumların güven içerisinde yaşayabilmesi açısından büyük önem taşıyan; birey ve toplum için birleştirici olduğuna inanılan ve arzu edilen davranışlar için ölçüt olarak kullanılan olgulardır (Alpöge, 2018, s. 10; Bağcı \& Elbir, 2013, s. 1321; Hökelekli, 2010, s. 5; Kaymakcan, 2010, s. 11). Yaşamının ilk evresinde kazandığı birçok davranışı hayatı boyunca devam ettirecek olan çocuğun, ailesinden edindiği temel değerler sonraki yaşamının şekillenmesi açısından büyük önem taşımaktadır (Hökelekli, 2010, s. 7; Yı1maz, 2010, s. 55).

Aileyle başlayan değerlerin kazanılması ve bireyin sosyal ilişkilerinde kazandığ 1 bu değerleri kullanabilmesinde aileden sonra gelen en etkili kurumun okul olduğu düşünülmektedir (Okumuş, 2010, s. 31). Bu nedenle çocuğun içinde yaşadığı toplumun değer yargılarına ve kültürel yapısına uygun davranış ve alışkanlıklarının şekillenmeye devam ettiği okul öncesi dönemin iyi bir şekilde 
planlanması gerekmektedir (Dereli İman, 2014, s. 262). Çocukların sevgi, sayg1, iş birliği, sorumluluk, hoşgörü, yardımlaşma, dayanışma ve paylaşma gibi toplumsal değer yargılarını yansıtan duygu ve davranışları geliştirmesi okul öncesi dönem eğitiminin temel hedefleri arasında yer almaktadır (Sakai, 2006, s. 40). Söz konusu bu hedeflerin gerçekleştirilmesinde müzik eğitiminin etkili bir süreç olduğu düşünülmekte; iyi planlanmış müzik etkinlikleri ile çocuğun sosyal, duygusal, fiziksel ve zihinsel gelişimlerinin olumlu yönde değişeceği düşünülmektedir (Seyrek \& Sun, 2002, s.32; Sığırtmaç, 2017, s.8).

Yapılan ulusal ve uluslararası çalışmalar incelendiğinde okul öncesi eğitimde değerler eğitimiyle ilgili araştırmaların yer aldığı görülmektedir. Öztürk Samur ve Deniz (2014) yapmış oldukları çalışmada değerler eğitimi programının 6 yaş çocuklarının sosyal ve duygusal gelişimlerine kalıcı yönde etkisi olduğunu tespit etmiştir. Bu bulgu, değerler eğitimine yönelik çalışmaların çocuğun gelişimine olumlu yönde katkısı olduğunu ve bu yönü ile okul öncesi eğitim programlarında yer verilmesi gerekliliğini ortaya koymaktadır. Karakuş (2015) "Okul Öncesi Döneme Hitap Eden Tema İçerikli Çizgi Filmlerin Değerler Eğitimine Katkısı Yönünden Değerlendirilmesi (Niloya Örneği)" isimli çalışmasında söz konusu çizgi filmde en çok sevgi, duyarlılık, hoşgörü ve iyilik değerlerini yansıtan örneklerin bulunduğunu ve bu değerleri çalışkanlık, dayanışma, saygı, sorumluluk ve yardımseverlik değerlerinin izlediğini belirlemiştir. Bu bulgu, Niloya isimli çizgi filmin çocukların değerler eğitimine katkıda bulunduğunu ve okul öncesi yaş grubu çocuklarına yönelik hazırlanan bu tür çizgi filmlerle çocukların değerler eğitimlerine yönelik benzer katkıların olabileceğini ortaya koymaktadır. Sözkesen ve Öztürk Samur (2015) çalışmalarında öykü temelli yaratıcı drama yöntemiyle değerler eğitimi programının 60-72 aylık çocukların değer gelişiminde etkili ve kalıcı sonuçları olduğunu; Kaya, Günay ve Aydın (2016) yapmış oldukları çalışmada okul öncesi dönemde drama yöntemiyle işlenen değerler eğitimi dersinin öğrencilerin değerlere ilişkin farkındalıklarını arttırmada etkili olduğunu; Zachrisen (2016) ise çalışmasında grup etkileşimi ve oyun yoluyla çocuklara demokratik değerlerin aktarılabileceğini tespit etmişlerdir. Bu çalışmalardan elde edilen bulgular okul öncesi dönem çocukların değerlere ilişkin farkındalıklarını arttırmada drama, grup etkileşimli çalışmalar ve oyunun önemini ortaya koymaktadır.

Amollo ve Lilian (2017) yapmış oldukları çalışmada öğretmenlerin bilinçli ya da bilinçsiz olarak okul öncesi dönemde değerlere yönelik eğitim verdiklerini, ancak örgün öğrenmeye yönelik planlı bir değer eğitimi programı olmadığını 
tespit etmişlerdir. Bu bulgu okul öncesi dönemde değerlerin öğretimine yönelik planlı bir öğretim programının olmasının ve öğretmenlerin de değer eğitiminin önemi konusunda farkındalıklarının arttırılmasının gerekliliğini ortaya koymaktadır.

Değerlere ilişkin bilgilerin temellendiği okul öncesi dönemde çocuklara kazandırılabilecek değerler sorumluluk, sevgi, saygı, hoşgörü, yardımseverlik, nezaket, arkadaşlık, işbirliği, dürüstlük ve öz denetim becerileri olarak sıralanabilir (Sapsağlam, 2016, s. 49). Çocuğun sosyal ve duygusal gelişiminde önemli araçlardan biri olarak düşünülen değerlerin okul öncesi eğitim etkinlikleri ile keşfettirilmesi ve kazandırılmasında müzik etkinliklerinin önemli katkılarının olacağı düşünülmektedir. Bu düşünce ile araştırmanın genel amacı okul öncesi müzik eğitimi kapsamında gerçekleştirilen etkinliklerde şarkılarla değerler eğitiminin çocukların farkındalık düzeyine etkisini belirlemek ve bu kapsamda okul öncesi müzik eğitiminde gerçekleştirilen etkinliklerde daha etkili ve verimli çalışmaların yapılmasına katkı sağlamaktır. Bu amaçla aşağıdaki sorulara yanıt aranmıştır:

1. Kontrol ve deney gruplarının ön test sonuçları arasında anlamlı fark var midir?

2. Kontrol grubunun ön test ve son test puanları arasinda anlamlı fark var midir?

3. Deney grubunun ön test ve son test puanları arasında anlamlı fark var mıdır?

4. Kontrol ve deney grubunun son test puanları arasında anlamlı bir fark var midir?

5. Kontrol ve deney grubunun gelişmeleri arasında anlamlı bir fark var mıdır?

\section{Yöntem}

Bu bölümde araştırmanın modeli, örneklemi ve verilerin elde edilmesine ilişkin bilgilere yer verilmiştir.

\section{Araştırma Modeli}

$\mathrm{Bu}$ araştırmada ön test-son test statik gruplu desen modeli kullanılmıştır. Ön test-son test kontrol gruplu deneme modellerinde yansız atama ile oluşturulmuş iki grup bulunur. Her iki gruba da deney öncesi ve sonrası ölçmeler yapılır (Karasar, 2009, s. 102). 


\section{Çalışma Grubu}

Bu araştırma 2018-2019 eğitim/öğretim yılında Bursa ili sınırları içinde bulunan, Milli Eğitim Bakanlığına bağlı okul öncesi eğitim kurumunda eğitim alan ve kolay örnekleme yöntemiyle ulaşılmış çocuklar ile yürütülmüştür. Araştırmanın çalışma grubunu 5 yaş grubunda eğitim alan iki ana sınıfı oluşturmaktadır. Öğrencilerin sınıfları değiştirilmeden, 15 'er öğrenciden oluşan bu iki sınıftan biri kontrol diğeri de deney grubuna rastgele olarak atanmıştır.

\section{Veri Toplama Araçları}

Araştırmanın uygulama sürecinde kullanılacak olan şarkı dağarcığı için Milli Eğitim Bakanlığı Temel Eğitim Genel Müdürlüğü Okul Öncesi Eğitim Programı'nda yer alan değerler tespit edilmiş ve üç alan uzmanından bu değerlerin (MEB, 2013, s. 27, 34) öğretimine uygun şark1 önerilerinde bulunmaları istenmiştir. Uzmanlara, şarkı önerisinde bulunurken çocukların dil ve müziksel gelişimlerinin ön planda tutulduğu, hedeflenen yaş grubunun sınırları ile Türk dili özellikleri ve söz-müzik ilişkisinin dikkate alındığı çocuk şarkılarını göz önünde bulundurmaları hatırlatılmıştır. Uzmanlar tarafından en çok önerilen güven, temizlik, arkadaşlık ve yardımseverlik değerleri ve bu değerlerin öğretilmesine yönelik olarak Tablo 1'de yer alan şarkılar çalışma kapsamına alınmıştır.

Tablo 1: Çalışma Kapsamında Kullanılan Şarkılar

\begin{tabular}{llll}
\hline Şarkı Adı & Besteci & Söz Yazarı & İlgili Değer \\
\hline Okula Geldim & Salih Aydoğan & Hamdi Tunçer & Arkadaşlık \\
\hline Yalancı & Fransız Ezgisi & Ahmet Muhtar Ataman & Güven \\
\hline Temiz Çocuk Ol & Mahir Dinçer & Mahir Dinçer & Temizlik \\
\hline Cennet Dünya & Mahir Dinçer & Mahir Dinçer & Yardımseverlik \\
\hline
\end{tabular}

Belirlenen değerlere ilişkin "Resimli Kartlar Testi" araştırmacı tarafından geliştirilmiş ve bu resimli kartlar çocukların söz konusu değerlerle ilgili farkındalık düzeylerini tespit etmek amacıyla ön test-son test olarak kullanılmıştır. $\mathrm{Bu}$ ölçme aracının kapsam geçerliği için bir alan uzmanı ve iki okul öncesi öğretmeni olmak üzere üç uzman görüşü alınmış, dönütler doğrultusunda düzeltmeler yapılarak "Resimli Kartlar Testinin” son şekli verilmiştir.

Değerlere ilişkin "Resimli Kartlar Testi" belirlenen değerleri yansıtan resimlerden oluşmaktadır. Uygulama sırasında resimli kartlar deney ve kontrol grubu öğrencilerine sırasıyla gösterilmiş, kartta gördükleri durum ile ilgili ne söylenmesi ve yapılması gerektiği sorulmuştur. Öğrencilerin verdiği cevaplar kaydedilmiş, bu kayıtlar üç alan uzmanına izletilerek 1 ile 5 aralığında puanla- 
ma yapılmıştır. Deneysel işlemin etkili olup olmadığının belirlenmesinde deney öncesi ve sonrası puanlar arasındaki gelişmeye bakılarak karar verilmiştir.

\section{Deneysel İşlem}

Araştırma kapsamında 5 yaş grubu iki okul öncesi sınıfı bulunmaktadır. Sınıflardan biri deney diğeri kontrol grubu olarak rastgele atanmıştır. Değerlere ilişkin resimli kartlar testi ön test olarak her iki gruba uygulanmış ve grupların uygulama öncesi eşitliği kartları doğru anlayabilme puanları açısından test edilmiştir. Deney grubuna söz konusu değerlere uygun olarak belirlenen şarkılar, kontrol grubuna ise müzik öğretmeninin eğitim süreci içerisinde program çerçevesinde belirlediği şarkılar çalıştırılmıştır. Uygulama 8 hafta boyunca devam etmiştir. Etkinlikler okul öncesi eğitim programlarında beş yaş grubuna yönelik olarak verilen 20-25 dakikalık müzik etkinlikleri süresi dikkate alınarak maksimum 25 dakikayı geçmeyecek şekilde haftada bir gün olarak gerçekleştirilmiştir (MEB, 2017, s.37). Uygulama sürecinin sonucunda değerlere ilişkin resimli kartlar testi son test olarak tekrar uygulanmıştır. Ön test ve son test sırasında öğrencilerin verdiği cevaplar sırasında video kaydı yapılmış ve üç alan uzmanı tarafindan değerlendirilmiştir.

\section{Verilerin Toplanması ve Çözümlenmesi}

Araştırmada verilerin toplanması ilgili literatürün taranması ve okul öncesi 5 yaş grubu çocuklardan oluşan örneklem grubuna ön test uygulamasının yapı1ması, araştırmanın eğitim sürecinin uygulanması ve son test uygulamasının yapılması aşamalarından oluşmaktadır.

Araştırmanın uygulama sürecinde okul öncesi eğitimin ilke ve amaçlarına uygun olarak ve uzman görüşleri de alınarak araştırmacı tarafindan tespit edilen şarkı dağarcığı kullanılarak müzik eğitimi gerçekleştirilmiştir. 8 haftalık eğitim süreci sonunda son test uygulaması yapılmıştır. Son test aşamasında araştırmacı ve iki alan uzmanı ölçme aracı ile ilgili gerekli değerlendirmeleri yapmışlardır. Tablo 2'de puanlayıcıların ölçme aracında yapmış oldukları değerlendirmenin tutarlı olup olmadığını gösteren Kendall's W uyum katsayıları verilmiştir. 
Tablo 2: Puanlayıcıların Ölçme Aracında Yapmış Oldukları Değerlendirmenin Tutarlı̆̆ına İlişkin Kendall W Uyum Katsayıları

\begin{tabular}{lllll}
\hline & N & W & df & p \\
\hline ÖN TEST & & & & \\
\hline Temizlik & 3 & .864 & 29 & $<.001$ \\
\hline Arkadaşlık & 3 & .682 & 29 & .001 \\
\hline Güven & 3 & .931 & 29 & $<.001$ \\
\hline Yardımseverlik & 3 & .905 & 29 & $<.001$ \\
\hline Toplam & 3 & .868 & 29 & $<.001$ \\
\hline SON TEST & & & & \\
\hline Temizlik & 3 & .976 & 29 & $<.001$ \\
\hline Arkadaşlık & 3 & .971 & 29 & $<.001$ \\
\hline Güven & 3 & .990 & 29 & $<.001$ \\
\hline Yardımseverlik & 3 & .977 & 29 & $<.001$ \\
\hline Toplam & 3 & .989 & 29 & $<.001$ \\
\hline
\end{tabular}

Tablo 2'de ön test ve son test alt boyut ve toplam puanları için Kendall W uyum katsayıları verilmiştir. Bu sayılar puanlayıcılar arasında uyum olduğunu göstermekte ve dolayısıyla ölçümlerin güvenirliğine kanıt oluşturmaktadır.

Araştırmanın genel amacı ve ana problemi çerçevesinde cevaplara aranan alt problemler olarak veriler bilgisayara aktarılarak istatistiksel çözümler için SPSS 23.0 paket programından yararlanılmıştır. İstatiksel anlamlılık için .05 anlamlılık düzeyi seçilmiştir. Hazırlanan şarkı dağarcığı ile değerler eğitimine yönelik olarak gerçekleştirilen müzik eğitiminin çocukların değerlere yönelik farkındalık düzeyleri üzerindeki etkisini belirlemek amacıyla yapılan ölçümlerde deney ve kontrol gruplarının ön test ve son test puanları elde edilmiştir. Puanların analizinde normal dağılımdan sapmalar ve çalışma grubunun küçüklüğü göz önünde bulundurularak non-parametrik testlerin uygulanmasına karar verilmiştir. Ön test ve son test arasındaki değişimlerin anlamlılığına ilişkin olarak Wilcoxon işaretli sıralama testleri uygulanmıştır. Grupların ön test puanları açısından farlılık gösterme durumları, son test puanları açısından farkl1lık gösterme durumları ve fark puanları arasındaki farklılıklar analiz edilirken Mann-Whitney U testi kullanılmıştır.

\section{Bulgular}

$\mathrm{Bu}$ bölümde veri toplama aracından elde edilen bulgulara yer verilmiştir.

Tablo 3’te kontrol ve deney gruplarının ön test puanlarına ilişkin Mann-Whitney $\mathrm{U}$ testi sonuçlarına yer verilmiştir. 
Tablo 3: Kontrol ve Deney Gruplarının Ön Test Puan Karşılaştırmalarına İlişkin Mann-Whitney U Testi Sonuçları

\begin{tabular}{lllllllll}
\hline \multirow{2}{*}{ Temizlik } & & $\mathbf{N}$ & $\boldsymbol{M}$ & $\boldsymbol{S D}$ & $\boldsymbol{M d n}$ & $\boldsymbol{U}$ & $\boldsymbol{z}$ & $\mathrm{p}$ \\
\hline \multirow{2}{*}{ Arkadaşlık } & Kontrol & 15 & 3.222 & 0.861 & 3.000 & \multirow{2}{*}{97.5} & -.651 & \multirow{2}{*}{.539} \\
\cline { 2 - 10 } & Deney & 15 & 3.356 & 0.802 & 3.000 & & & \\
\hline \multirow{2}{*}{ Güven } & Kontrol & 15 & 1.644 & 0.672 & 1.667 & 107.5 & -.213 & .838 \\
\cline { 2 - 10 } & Deney & 15 & 1.578 & 0.584 & 1.333 & & & \\
\hline \multirow{2}{*}{ Yardımseverlik } & Kontrol & 15 & 1.378 & 0.872 & 1.000 & 101.5 & -.586 & .653 \\
\cline { 2 - 9 } & Deney & 15 & 1.378 & 0.689 & 1.000 & & & \\
\hline \multirow{2}{*}{ Toplam } & Kontrol & 15 & 2.800 & 0.842 & 3.000 & 96.0 & -.705 & .512 \\
\cline { 2 - 9 } & Deney & 15 & 2.978 & 0.955 & 3.000 & & & \\
\hline
\end{tabular}

Tablo 3'e göre, kontrol grubunun $(\mathrm{M}=3.222$, $\mathrm{Mdn}=3.000)$ ve deney grubunun $(\mathrm{M}=3.356, \mathrm{Mdn}=3.000)$ temizlik puanları arasındaki fark istatistiksel olarak anlamlı değildir, $\mathrm{U}=97.5, \mathrm{z}=-.651, \mathrm{p}=.539$. Arkadaşlık puanları açısından kontrol grubu $(\mathrm{M}=1.644, \mathrm{Mdn}=1.667)$ ve deney grubu $(\mathrm{M}=1.578, \mathrm{Mdn}=1.333)$, $\mathrm{U}=107.5, \mathrm{z}=-.213, \mathrm{p}=.838$ arasinda anlamlı bir fark yoktur. Kontrol grubu $(\mathrm{M}=1.378, \mathrm{Mdn}=1.000)$ ve deney grubu $(\mathrm{M}=1.378, \mathrm{Mdn}=1.000)$ güven puanlar1 arasındaki fark istatistiksel olarak anlamlı değildir, $U=101.5, \mathrm{z}=-.586, \mathrm{p}=.653$. Yardım severlik puanları açısından kontrol grubu $(\mathrm{M}=2.800, \mathrm{Mdn}=3.000)$ ve deney grubu $(\mathrm{M}=2.978, \mathrm{Mdn}=3.000), \mathrm{U}=96.0, \mathrm{z}=-.705, \mathrm{p}=.512$ puanlar1 arasinda anlamlı bir fark yoktur. Kontrol grubunun ön test toplam puanları $(\mathrm{M}=9.044$, $\mathrm{Mdn}=8.333)$, ile deney grubunun puanları $(\mathrm{M}=9.289, \mathrm{Mdn}=8.667)$, arasinda anlamli fark yoktur $(\mathrm{U}=97.5, \mathrm{z}=-.624, \mathrm{p}=.539)$.

Tablo 4'te kontrol grubunun ön test ve son test puanlarına ilişkin Wilcoxon işaretli sıralama testi sonuçlarına yer verilmiştir.

Tablo 4: Kontrol Grubunun Ön Test ve Son Test Puanlarına İlişkin Wilcoxon Testi Sonuçları

\begin{tabular}{lllllllll}
\hline \multirow{2}{*}{ Temizlik } & & $\mathbf{N}$ & $\boldsymbol{M}$ & $\boldsymbol{S D}$ & $\boldsymbol{M d n}$ & $\boldsymbol{T}$ & $\boldsymbol{z}$ & $\boldsymbol{p}$ \\
\hline \multirow{2}{*}{ Arkadaşlık } & Ön test & 15 & 3.222 & 0.861 & 3.000 & 43.0 & 1.602 & .109 \\
\cline { 2 - 9 } & Son test & 15 & 3.733 & 1.156 & 3.000 & & & .049 \\
\hline \multirow{2}{*}{ Güven } & Ön test & 15 & 1.644 & 0.672 & 1.667 & 39.0 & 1.965 & \\
\cline { 2 - 9 } & Son test & 15 & 2.667 & 1.755 & 1.667 & & 1.000 & .317 \\
\hline \multirow{2}{*}{ Yardımseverlik } & Ön test & 15 & 1.378 & 0.872 & 1.000 & 1.0 & & .011 \\
\cline { 2 - 9 } & Son test & 15 & 1.422 & 0.955 & 1.000 & & & \\
\hline \multirow{2}{*}{ Toplam } & Ön test & 15 & 2.800 & 0.842 & 3.000 & 93.0 & 2.550 & .003 \\
\cline { 2 - 8 } & Son test & 15 & 3.644 & 1.231 & 3.667 & & & \\
\hline
\end{tabular}


Tablo 4'te de görüldüğü gibi kontrol grubunun temizlik değeri ön test $(M=3.222, M d n=3.000)$ ve son test puanlar1 $(M=3.733, M d n=3.000), T=43.0$, $z=1.602, p=.109$ arasında anlamlı bir fark bulunamamıştır. Arkadaşlık değeri ön test $(M=1.644, M d n=1.667)$ ve son test puanları $(M=2.667, M d n=1.667)$, arasında anlamlı fark bulunmuştur $T=39.0, z=1.965, p=.049$. Güven değeri ön test $(M=1.378, M d n=1.000)$ ve son test puanlar1 $(M=1.422, M d n=1.000)$, $T=1.0, z=1.000, p=.317$ arasında anlamlı bir fark bulunamamıştır. Yardımseverlik ön test $(M=2.800, M d n=3.000)$ ve son test puanları $(M=3.644, M d n=3.667)$, $T=93.0, z=2.550, p=.011$ arasında düşük düzeyde anlamlı fark bulunmuştur. Toplamda kontrol grubunun ön testi $(M=9.044, M d n=8.333)$ ile son testi $(M=11.467, M d n=12.000), T=111.5, z=2.927, p=.003$ arasinda anlamlı bir fark bulunmuştur.

Tablo 5'te deney grubunun ön test ve son test puanları arasındaki Wilcoxon işaretli sıralama testi sonuçlarına yer verilmiştir.

\begin{tabular}{lllllllll}
\hline Tablo 5: Deney Grubunun Ön Test ve Son Test Puanlarına İlişkin Wilcoxon Testi Sonuçları \\
\hline \multirow{2}{*}{ Temizlik } & & $\mathbf{N}$ & $\boldsymbol{M}$ & $\boldsymbol{S D}$ & $\boldsymbol{M} \boldsymbol{n} \boldsymbol{T}$ & $\boldsymbol{T}$ & $\boldsymbol{z}$ & $\mathrm{p}$ \\
\hline \multirow{2}{*}{ Arkadaşlık } & Ön test & 15 & 3.356 & 0.802 & 3.000 & 75.0 & 2.849 & .004 \\
\cline { 2 - 10 } & Son test & 15 & 4.489 & 1.068 & 5.000 & & & \\
\hline \multirow{2}{*}{ Güven } & Ön test & 15 & 1.578 & 0.584 & 1.333 & 120.0 & 3.427 & .001 \\
\cline { 2 - 10 } & Son test & 15 & 4.978 & 0.086 & 5.000 & & & \\
\hline \multirow{2}{*}{ Yardımseverlik } & Ön test & 15 & 1.378 & 0.689 & 1.000 & 105.0 & 3.325 & .001 \\
\cline { 2 - 10 } & Son test & 15 & 3.822 & 1.154 & 4.000 & & & \\
\hline \multirow{2}{*}{ Toplam } & Ön test & 15 & 2.978 & 0.955 & 3.000 & 105.0 & 3.309 & .001 \\
& Son test & 15 & 4.978 & 0.086 & 5.000 & & & \\
\hline & Ön test & 15 & 9.289 & 2.089 & 8.667 & 120.0 & 3.408 & .001 \\
\cline { 2 - 8 } & Son test & 15 & 18.270 & 1.899 & 19.00 & & & \\
\hline
\end{tabular}

Tablo 5'te görüldüğ ü gibi, temizlik ön test $(\mathrm{M}=3.356, \mathrm{Mdn}=3.000)$ ve son test puanları $(\mathrm{M}=4.489, \mathrm{Mdn}=5.000), \mathrm{T}=75.0, \mathrm{z}=2.849, \mathrm{p}=, 004$ arasındaki fark anlamlı bulunmuştur. Arkadaşlık ön test puanları $(\mathrm{M}=1.578, \mathrm{Mdn}=1.333)$ son testte $(M=4.978, M d n=5.000)$, anlamlı olarak gelişsmiştir, $T=120.0, z=3.427$, $\mathrm{p}=.001$. Güven ön test puanları $(\mathrm{M}=1.378, \mathrm{Mdn}=1.000)$ ile son test puanla$\mathrm{r} 1(\mathrm{M}=3.822, \mathrm{Mdn}=4.000), \mathrm{T}=105.0, \mathrm{z}=3.325, \mathrm{p}=.001$ arasında anlamlı fark vardır. Yardımseverlik ön test puanları $(\mathrm{M}=2.978, \mathrm{Mdn}=3.000)$, son test puanlarından $(\mathrm{M}=4.978, \mathrm{Mdn}=5.000)$, anlamlı olarak daha düşük bulunmuştur, $\mathrm{T}=105.0, \mathrm{z}=3.309, \mathrm{p}=.001$. Deney grubunun ön test toplam puanları $(\mathrm{M}=9.289$, $\mathrm{Mdn}=8.667)$ son testte $(\mathrm{M}=18.270, \mathrm{Mdn}=19.000)$ anlamlı bir şekilde artmıştır, $\mathrm{T}=120.0, \mathrm{z}=3.3408, \mathrm{p}=.001$. 
Tablo 6' da kontrol ve deney gruplarının son test puanlarına ilişkin Mann-Whitney U testi sonuçlarına yer verilmektedir.

Tablo 6: Kontrol ve Deney Gruplarının Son Test Puanlarına İlişkin Mann-Whitney U Testi Sonuçları

\begin{tabular}{lllllllll}
\hline \multirow{2}{*}{ Temizlik } & & $\mathbf{N}$ & $\boldsymbol{M}$ & $\boldsymbol{S D}$ & $\boldsymbol{M d n}$ & $\boldsymbol{U}$ & $\boldsymbol{z}$ & $\boldsymbol{p}$ \\
\hline \multirow{2}{*}{ Arkadaşlik } & Kontrol & 15 & 3.733 & 1.156 & 3.000 & 74.0 & -1.818 & .116 \\
\cline { 2 - 9 } & Deney & 15 & 4.489 & 1.068 & 5.000 & & & \\
\hline \multirow{2}{*}{ Güven } & Kontrol & 15 & 2.667 & 1.755 & 1.667 & 40.0 & -3.486 & .002 \\
\cline { 2 - 9 } & Deney & 15 & 4.978 & 0.086 & 5.000 & & & $<.001$ \\
\hline \multirow{2}{*}{ Yardımseverlik } & Kontrol & 15 & 1.422 & 0.955 & 1.000 & 17.0 & -4.249 & \\
\hline \multirow{2}{*}{ Toplam } & Deney & 15 & 3.822 & 1.154 & 4.000 & & -3.490 & .002 \\
\cline { 2 - 9 } & Kontrol & 15 & 3.644 & 1.231 & 3.667 & 40.0 & & $<.001$ \\
\hline
\end{tabular}

Tablo 6'ya göre temizlik puanları açısından kontrol grubu $(\mathrm{M}=3.733$, $\mathrm{Mdn}=3.000)$ ve deney grubu $(\mathrm{M}=4.489, \mathrm{Mdn}=5.000)$ arasindaki fark istatistiksel olarak anlamlı değildir, $\mathrm{U}=74.0, \mathrm{z}=-1.818, \mathrm{p}=.116$. Arkadaşlık puanları açısından kontrol grubu $(\mathrm{M}=2.667, \mathrm{Mdn}=1.667)$ ve deney grubu $(\mathrm{M}=4.978$, $\mathrm{Mdn}=5.000), \mathrm{U}=40.0, \mathrm{z}=-3.486, \mathrm{p}=.002$ arasında anlamlı bir fark vardır. Kontrol grubu güven puanları $(\mathrm{M}=1.422, \mathrm{Mdn}=1.000)$ ve deney grubu güven puanları $(\mathrm{M}=3.822, \mathrm{Mdn}=4.000)$ arasındaki fark istatistiksel olarak anlamlıdır, $\mathrm{U}=17.0, \mathrm{z}=-4.249, \mathrm{p}=<.001$. Yardımseverlik puanları açısından kontrol grubu $(\mathrm{M}=3.644, \mathrm{Mdn}=3.667)$ ve deney grubu $(\mathrm{M}=4.978, \mathrm{Mdn}=5.000)$, arasinda anlamlı fark vardır, $U=40.0, z=-3.490, p=.002$. Kontrol grubu son test toplam puanlar1 $(M=11.467, M d n=12.000)$, deney grubundan $(M=18.270, M d n=19.000)$, istatistiksel olarak daha düşüktür $\mathrm{U}=10.5, \mathrm{z}=-4.295, \mathrm{p}=<.001$.

Tablo 7'de kontrol ve deney gruplarının gelişmeleri (son test - ön test) arasındaki farka ilişkin Mann-Whitney U testi sonuçlarına yer verilmiştir.

Tablo 7: Kontrol ve Deney Gruplarının Gelişmelerinin (Son Test - Ön Test Farklarının) Karşılaştırılmasına İlişkin Mann-Whitney U Testi Sonuçları

\begin{tabular}{|c|c|c|c|c|c|c|c|c|}
\hline & & $\mathbf{N}$ & $M$ & $S D$ & $M d n$ & $U$ & $z$ & $p$ \\
\hline \multirow{2}{*}{ Temizlik } & Kontrol & 15 & 0.511 & 1.007 & 0.000 & 152.0 & 1.668 & .106 \\
\hline & Deney & 15 & 1.133 & 0.998 & 1.667 & & & \\
\hline \multirow{2}{*}{ Arkadaşlık } & Kontrol & 15 & 1.022 & 1.601 & 0.000 & 192.5 & 3.352 & $<.001$ \\
\hline & Deney & 15 & 3.400 & 0.580 & 3.667 & & & \\
\hline \multirow{2}{*}{ Güven } & Kontrol & 15 & 0.044 & 0.172 & 0.000 & 216.0 & 4.609 & $<.001$ \\
\hline & Deney & 15 & 2.444 & 1.614 & 3.000 & & & \\
\hline \multirow{2}{*}{ Yardımseverlik } & Kontrol & 15 & 0.844 & 1.083 & 0.667 & 176.0 & 2.651 & .008 \\
\hline & Deney & 15 & 2.000 & 0.960 & 2.000 & & & \\
\hline \multirow{2}{*}{ Toplam } & Kontrol & 15 & 2.422 & 2.259 & 2.333 & 219.0 & 4.419 & $<.001$ \\
\hline & Deney & 15 & 8.978 & 2.461 & 9.000 & & & \\
\hline
\end{tabular}


Tablo 7'ye göre temizlik puanları açısından kontrol grubundaki gelişme $(\mathrm{M}=0.511, \mathrm{Mdn}=0.000)$ ve deney grubundaki gelişme $(\mathrm{M}=1.133, \mathrm{Mdn}=1.667)$ arasındaki fark istatistiksel olarak anlamlı değildir, $U=152.0, \quad z=1.668$, $\mathrm{p}=.106$. Arkadaşlık puanları açısından kontrol grubundaki gelişme $(\mathrm{M}=1.022$, $\mathrm{Mdn}=0.000)$ ve deney grubundaki gelişme $(\mathrm{M}=3.400, \mathrm{Mdn}=3.667)$, arasında anlamlı bir fark vardır, $\mathrm{U}=192.5, \mathrm{z}=3.352, \mathrm{p}=<.001$. Kontrol grubunun güven puanlarındaki gelişme $(\mathrm{M}=0.044, \mathrm{Mdn}=0.000)$ ve deney grubu güven puanlarındaki gelişme $(\mathrm{M}=2.444, \mathrm{Mdn}=3.000)$ arasındaki fark istatistiksel olarak anlamlıdır, $\mathrm{U}=216.0, \mathrm{z}=4.609, \mathrm{p}=<.001$. Yardımseverlik puanları açısından kontrol grubundaki gelişme $(\mathrm{M}=0.844, \mathrm{Mdn}=0.667)$ ve deney grubundaki gelişme ( $\mathrm{M}=2.000, \mathrm{Mdn}=2.000)$, arasında anlamlı fark vardır, $\mathrm{U}=176.0, \mathrm{z}=2.651$, $\mathrm{p}=.008$. Kontrol grubu toplam puanlarındaki gelişme $(\mathrm{M}=2.422$, $\mathrm{Mdn}=2.333)$, deney grubundan $(\mathrm{M}=8.978, \mathrm{Mdn}=9.000)$, istatistiksel olarak daha düşüktür $\mathrm{U}=219.0, \mathrm{z}=4.419, \mathrm{p}=<.001$.

\section{Sonuç ve Tartışma}

Şarkılarla gerçekleştirilen müzik etkinlikleri yolu ile çocukların değerlere yönelik farkındalıklarında herhangi bir değişikliğin olup olmadığını belirlemeye yönelik olarak gerçekleştirilen bu araştırmadan elde edilen bulgular doğrultusunda aşağıdaki sonuçlara ulaşılmıştır.

Araştırma kapsamında belirlenen değerler deney grubuna şarkılar yoluyla öğretilmiştir. Yapılan analizler sonucunda deney ve kontrol gruplarının ön test puanları arasında istatistiksel olarak anlamlı bir fark bulunamamıştır. Kontrol grubunun ön test ve son test puanları arasında anlamlı bir farkın olup olmad1ğını tespit etmek amaciyla gerçekleştirilen Wilcoxon işaretli sıralama testi sonucunda kontrol grubunun arkadaşlık ve yardımseverlik alt boyutları ile toplam puanlarında son test lehine anlamlı düzeyde $(p<.05)$ fark olduğu belirlenmiştir. Deney grubunun ön test ve son test puanları analiz edildiğinde ise tüm alt boyutlar ve toplam puanlarda son test lehine fark olduğu $(p<.05)$ saptanmıştır.

Deney ve kontrol grubunun son test puanları arasında anlamlı bir farkın olup olmadığını tespit etmek amacıyla gerçekleştirilen Mann Whitney U testi sonucuna göre temizlik alt boyutu hariç tüm alt boyutlar ve toplam puanlarda deney grubunun lehine anlamlı fark $(p<.05)$ gözlenmiştir. Temizlik alt boyutunda her ne kadar deney grubu daha yüksek puan almış olsa da fark anlamlı bulunmamıştır.

Grupların gelişmeleri arasındaki farkı belirlemek için son test puanlarından 
ön test puanları çıkartılmış ve gruplar fark puanları açısından karşılaştırılmıştır. Yapılan analiz sonucunda tüm alt boyutlar ve toplam puanda deney grubu fark puanlarının anlamlı derecede $(p<.05)$ daha yüksek olduğu görülmüştür.

$\mathrm{Bu}$ analizlerden yola çıkarak iki grupta da gelişme görülmekle birlikte deney grubundaki gelişimin çok daha yüksek olduğu söylenebilir. Bununla birlikte kontrol grubunun arkadaşlık ve yardımseverlik puanlarında gelişme olduğu görülmüştür. $\mathrm{Bu}$ durum, ön test ve son test arasında geçen sürede şarkılarla verilen değerler eğitimi olmaksızın da çocukların değerlere yönelik farkındalıklarının geliştiğini, söz konusu değerlerin bu değerlere yönelik şarkılarla desteklendiğinde gelişimin arttığını düşündürmektedir.

Literatür taramasında değerlerin öğrencilere kazandırılmasına yönelik farklı çalışmaların yapıldığı görülmektedir. Müzik eğitimi yoluyla değerlerin öğrencilere kazandırılmasına yönelik Onuray Eğilmez (2016)'in yapmış olduğu çalışmada farklı etnik kökene sahip öğrencilerin toplumsal değerlere yönelik alg1larını incelemek üzere yazarın kendisi tarafından bestelenen 10 şarkı öğrenciler ile çalışılmış; çalışmanın sonucunda öğrencilerin toplumsal değerlere yönelik algılarının olumlu yönde değiştiği belirlenmiştir. Onuray Eğilmez (2016)'in şarkılar yoluyla değerlere yönelik farkındalıkların geliştirilebildiğini gösteren araştırma sonuçları çalışmamızdaki sonuçlarla benzerlik göstermektedir. Sonsel (2018) yapmış olduğu çalışmada ise ilköğretim müzik dersi müfredatında yer alan şarkıları evrensel değerlere uygunluğu açısından incelemiş, araştırmanın sonucunda müfredatta yer alan şarkılarda sevgi, sorumluluk ve mutluluk değerlerine yer verildiği, sayg1 ve hoşgörü değerlerine kısmen yer verildiği; dürüstlük, alçakgönüllülük ve sadelik değerlerine ise yer verilmediği tespit edilmiştir. Araştırmamızın sonucunda çocukların değerlere yönelik farkındalıklarının şarkılar yoluyla olumlu yönde geliştiğine ilişkin elde edilen bulgular da göz önünde bulundurularak, okul öncesi ve ilköğretim müzik öğretim programlarında çeşitli değerlerin öğretilmesine yönelik daha fazla şarkıya yer verilmesinin gerekli olduğu düşünülmektedir.

Bununla birlikte çocuklara değer eğitiminin kazandırılmasına yönelik olarak farklı çalışmaların da yapıldığı görülmektedir. Kolaç (2010) yapmış olduğu çalışmada Milli Eğitim Bakanlığı tarafından hazırlanan Türkçe Öğretim Programlarında bulunan "değer" ve "hoşgörü” kavramlarını incelemiş, araştırmanın sonucunda Türkçe derslerinde değerlere ve hoşgörüye yeteri kadar yer verilmediğini belirlemiştir. Bu bulgu Milli Eğitim Bakanlığ tarafindan hazırlanan öğretim programlarında değer eğitimine daha ayrıntılı bir şekilde yer verilmesi 
gerektiğini ortaya koymaktadır. Deveci, Belet ve Türe (2013) yapmış oldukları çalışmada Dede Korkut hikâyelerinde hangi değerlere yer verildiğini tespit etmeyi amaçlarmışlardır. Araştırmanın sonucunda aile birliği, sevgi, dürüstlük, sayg1, estetik, cesaret, onurlu olma, dayanışma, vatanseverlik, cömertlik, merhamet, toplumsal ve dini değerlerine yer verildiği tespit edilmiş ve ilköğretim ders programlarında değer eğitimi etkinliklerinde Dede Korkut hikâyelerine yer verilebileceğini ifade etmişlerdir. Buradan yola çıkarak değerlerin kazandırılmasına yönelik olarak gerçekleştirilecek etkinliklerde hikâyelere yer verilebileceği; okul öncesi eğitimde yer alan derslerde bu tür destansı hikâyeler yolu ile kültürel değerlerin aktarılmasında daha kalıcı izli sonuçlar ortaya çıkabileceği düşünülmektedir. Bu amaç ile öğretmenlere değer kazanımına yönelik materyal hazırlama ve ders içerisinde buna yönelik çalışmalar yapma amacına yönelik hizmet içi eğitim çalışmaları gerçekleştirilebilir.

Karagöz (2013) yapmış olduğu çalışmada ilköğretim 5. sınıf öğrencilerine değerlerin kazandırılmasında ve öğrencilerin farkındalık düzeylerinin arttırılmasında okul şarkılarının etkili bir araç olup olmadığ 1 belirlemeyi amaçlamış ve araştırmanın sonuncunda okul şarkıları ile yapılan müzik eğitiminin çocukların değer eğitimine katkı sağladığını ve değerlere ilişkin farkındalık düzeylerinin artmasında etkili olduğunu tespit etmiştir. Bu bulgu değer kazanımında müzik eğitiminde şarkıların önceden belirlenen amaçlar doğrultusunda etkili bir araç olarak kullanılabileceğini göstermektedir. Bu nedenle tüm kademelerde müzik ders programlarında değer kazanımına yönelik hedefler belirlenmeli ve bu hedeflere yönelik okul şarkılarına programlarda yer verilmelidir.

Özer ve Çam Aktaş (2019) yapmış oldukları çalışmada okul öncesi eğitim programı ile hayat bilgisi eğitim programlarını ele aldığı değerler açısından karşılaştırmış ve birbirini tamamlama durumlarını belirlemeyi amaçlamıştır. Araştırmanın sonucunda her iki programın sorumluluk ve özdenetim gibi bazı değerlerle birbirini tamamladığını; sevgi, saygı gibi bazı değerlerin ise birbirini tamamlamadığını tespit etmişlerdir. Ayrıca her iki öğretim programının adalet, dostluk gibi bazı değerlere kazanımlarında hiç yer vermediğini belirlemişlerdir. Bu bulgulardan yola çıkarak okulda verilecek değer eğitiminin kalıc1lığının sağlanabilmesi ve pekiştirilebilmesi amaci ile okul öncesinden ortaöğretime kadar eğitimin tüm aşamalarında değer eğitimine yönelik olarak tüm ders kazanımlarının birbirini destekler nitelikte olmasının gerekli olduğunu ortaya çıkmaktadır. 
Öğrenmenin hızlı bir şekilde gerçekleştiği okul öncesi dönemdeki eğitim çocukların bilişsel, duyuşsal ve devinişsel gelişimleri için büyük önem taşımaktadır. Bu nedenle hem müziksel hem de diğer zekâ türlerinin gelişimine katkısı olduğu düşünülen müzik eğitiminin okul öncesi eğitimde önemli bir yerinin olduğu düşünülmektedir. Bu kapsamda gerçekleştirilen müzik etkinliklerinde kullanılan şarkılar çocuklara değer aktarımı için bir firsat olarak değerlendirilebilir. Bu nedenle okul öncesi müzik etkinliklerinde kullanılacak şarkıların evrensel değerleri barındıran, çocukların farkındalık düzeyini arttıracak ve onların davranışlarına yön verecek kazanımları edinmelerini sağlayacak nitelikte olması gerekli görülmektedir. Çünkü geleceğe yön verecek, toplumu şekillendirecek çocukların evrensel değerleri de içine alan bir eğitim programı dâhilinde eğitilmeleri onların farkındalık düzeyini etkileyecektir.

Okul öncesi dönemde gerçekleştirilecek müzik eğitiminin çocuğun yaş, ilgi ve ihtiyacına göre planlı ve programlı etkin uygulamalarla gerçekleştirilmesi gerekli görülmektedir. Çünkü çocuğun sosyal, duygusal, fiziksel ve zihinsel gelişimlerini destekleyecek şekilde gerçekleştirilen bir müzik eğitimi programı, onun aynı zamanda estetik düşünce ve beğeni düzeyini geliştirip, değer yargılarının da oluşumuna katkı sağlayacaktır. Bu nedenle okul öncesi eğitimde gerçekleştirilecek müzik eğitiminin çocuğun yaş ve düzeyine uygun olarak planlanması, müzik eğitimi programının müzik eğitiminin gerektirdiği yöntem ve kapsam göz önüne alınarak düzenlenmesi çocukların ileriki yaşamlarına yön vermesi açısından gerekli ve önemli görülmektedir.

\section{Kaynakça}

Alpöge, G. (2018). Okul öncesinde değerler eğitimi. Ankara: Bilgi.

Amollo, O. P., \& Lilian, G. K. (2017). Teacher position in spurring value based education in early learning in Nairobi County, Kenya: Addressing support of values in school environment. Journal of Education and Learning, 6(3), 203. doi: $10.5539 /$ jel.v6n3p194

Aral, N. (2006). Anaokulunda devam eden altı yaş grubundaki çocukların kavram gelişiminde bilgisayar destekli öğretimin incelenmesi. Ankara: Ankara Üniveristesi.

Aral, N., Kandır, A., \& Can Yaşar, M. (2000). Okul öncesi eğitim ve anasınıfi programları. İstanbul: YA-PA.

Bağc1, C., \& Elbir, B. (2013). Değerler eğitimi üzerine yapılmış lisansüstü düzeyindeki çalışmaların değerlendirilmesi. Turkish Studies-International 
Periodical For The Languages, Literature and History of Turkish or Turkic Volume, 8(1), 1321-1333.

Dereli İman, E. (2014). The effect of the values education programme on 5.5-6 year old children's social development: social skills, psycho-social development and social problem solving skills. Educational Sciences: Theory \& Practice, 14(1), 262-268. doi: 10.12738/estp.2014.1.1679

Deveci, H., Belet, D., \& Türe, H. (2013). Dede korkut hikayelerinde yer alan değerler. Elektronik Sosyal Bilimler Dergisi, 12(46), 294-321.

Erbay, E. (2008). Okul öncesi eğitim alan ve almayan ilköğretim birinci sinıf öğrencilerin sosyal becerilere sahip olma düzeyleri (Yayımlanmamış yüksek lisans tezi). Pamukkale Üniversitesi, Sosyal Bilimler Enstitüsü, Denizli.

Gül, G. (2012). Okul öncesi altı yaş çocukları için oluşturulan şarkı dağarcı̆̆ının müziksel gelişim düzeylerine etkisi (Yayımlanmamış doktora tezi). Bursa Uludağ Üniversitesi, Eğitim Bilimleri Enstitüsü, Bursa.

Gürkan, T. (2016). Okul öncesi eğitim programları. R. Zembat (Eds.), Okul öncesinde özel öğretim yöntemleri. Ankara: Anı.

Hökelekli, H. (2010). Modern eğitimde yeni bir paradigma: Değerler eğitimi. Ĕgitime Bakış Dergisi, 6(18), 4-10.

Kantarc1, M. (2014). Okul Öncesi ĕgitim ve önemi. S. Seven (Eds.), Okul Öncesi Eğitime Giriş. Ankara: Pegem

Karagöz, B. (2013). İlköğretim öğrencilerine değerlerin okul şarkıları yoluyla kazandırılması (Yayımlanmamış doktora tezi). İnönü Üniversitesi, Eğitim Bilimleri Enstitüsü, Malatya.

Karakuş, N. (2015). Okul öncesi döneme hitap eden tema içerikli çizgi filmlerin değerler eğitimine katkısı yönünden değerlendirilmesi (Niloya örneği). Değerler Eğitimi Dergisi, 12(30), 251-277. Erişim adresi: http://proxy. wexler.hunter.cuny.edu/login?url=http://search.ebscohost.com/login.aspx?direct $=$ true $\& \mathrm{db}=$ eue $\& A N=115719072 \&$ site=ehost-live

Karasar, N. (2009). Bilimsel araştırma yöntemi. Ankara: Nobel.

Kaya, Y., Günay, R., \& Aydın, H. (2016). Okul öncesi eğitimde drama yöntemi ile işlenen değerler eğitimi derslerinin farkındalık düzeyi üzerindeki etkisi. Sakarya University Journal of Education, 6(1), 23. doi: 10.19126/suje.76036

Kaymakcan, R. (2010). Değer kavramı ve gençlerin dini değerleri. Eğitime Bakış Dergisi, 6(18), 10-15.

Kolaç, E. (2010). Hacı Bektaş Veli, Mevlana ve Yunus felsefesiyle Türkçe derslerinde değerler ve hoşgörü eğitimi. Türk Kültürü ve Hacı Bektaş Veli 
Araştırma Dergisi, 55, 193-208. Erişim adresi: http://isamveri.org/pdfdrg/ D01093/2010_55/2010_55_KOLACE.pdf

Kuru Turaşl1, N. (2015). Okul öncesi eğitimin tanımı, kapsamı ve önemi. İçinde. G. Haktanır (Eds.). Okul öncesi eğitime giriş. Ankara: Anı.

Milli Eğitim Bakanlığı. (2013). Okul öncesi eğitim programı, Ankara: MEB.

Milli Eğitim Bakanlığı. (2017). Milli Ĕ̆itim Bakanlı̆̆ı çocuk gelişimi ve eğitimi müzik etkinlikleri. Ankara: MEB.

Oktay, A. (2003). 21. yüzyıla girerken dünyada yaşanan değişimler ve erken çocuk eğitimi. İçinde (s. 18-30). M. Sevinç (Ed.). Erken çocuklukta gelişim ve eğitimde yeni yaklaşımlar. İstanbul: Morpa.

Okumuş, E. (2010). Toplum ve ahlak eğitimi. Eğitime Bakış Dergisi, 6(18), 28-32.

Onuray Eğilmez, H. (2016). Effects of songs containing social messages on the perceptions of Romani students about social values. Anthropologist, 24(2), 591-597. doi: 10.1080/09720073.2016.11892053

Özer, M., \& Çam Aktaş, B. (2019). Değerler eğitimi devamlılı̆̆1: Okul öncesi eğitim programından hayat bilgisi öğretim programına. Ilkögrretim Online, 18(1), 389-405. Erişim adresi: http://ilkogretim-online.org.tr/index.php/io/ article/view/3115/2500

Öztürk Samur, A., \& Deniz, M. E. (2014). Değerler eğitimi programının 6 yaş çocuklarının sosyal ve duygusal gelişimlerine etkisi. Kuramsal Eğitimbilim, 7(4), 463-481. doi: 10.5578/keg.6986

Sakai, A. (2006). Japonya ve Türkiye'de okul öncesi eğitimin tarihsel gelişimi ile Japon ve Türk annelerin okul öncesi eğitim ile ilgili görüşlerinin karşılaştırılması (Yayımlanmamış yüksek lisans tezi). Marmara Üniversitesi, Eğitim Bilimleri Enstitüsü, İstanbul.

Sapsağlam, Ö. (2016). Okul öncesi dönem ve değerler eğitimi. E. Ömeroğlu (Eds.), Okul öncesi dönemde karakter ve değerler eğitimi: Teoriden uygulamaya. Ankara: Pegem.

Seyrek, H., \& Sun, M. (2002). Okul öncesi eğitiminde müzik. İzmir: MEY.

Sığırtmaç, A. (2017). Okul öncesi dönemde müzik eğitimi. Ankara: Eğiten Kitap Yayınları.

Sonsel, Ö. B. (2018). Analysis of the children's songs in 2017 elementary school music lesson curriculum in terms of universal values. Journal of Education and Training Studies, 6(11), 82. doi: 10.11114/jets.v6i11.3531

Sözkesen, A., \& Öztürk Samur, A. (2015). 60-72 aylık çocukların değer eğitiminde öykü temelli yaratıcı drama yönteminin etkisi. Ondokuz Mayı Üniversitesi Eğitim Fakültesi Dergisi, 36(2), 105-117. 
Yılmaz, H. (2010). Çocuğun ailede kazanacağı önemli bir değer: Kanaatkârlık. Ĕgitime Bakış Dergisi, 6(18), 55-58.

Zachrisen, B. (2016). The contribution of different patterns of teachers' interactions to young children's experiences of democratic values during play. International Journal of Early Childhood, 48(2), 179-192. doi: 10.1007/s13158016-0166-0

Zembat, R. (2005). Okul öncesi eğitimde nitelik. A. Oktay \& Ö. P. Unutkan (Eds.), Okul öncesi eğitimde güncel konular. İstanbul: Morpa. 
Extended Abstract

\section{The Impact of Values Education with Songs on the Awareness Level of Preschool Children}

Gülnihal GÜL, Corresponding Author, Associate Professor.

Bursa Uludağ University, Faculty of Education, Turkey.

gulnihalgul@gmail.com

http://orcid.org/0000-0001-9437-2419

Seda MINTAŞ, Teacher.

Republic of Turkey Ministry of National Education, Turkey.

mintasseda@gmail.com

http://orcid.org/0000-0003-3631-7889

Doruk ENGÜR, Assistant Professor.

Bursa Uludag University, Faculty of Education, Turkey.

dorukengur@gmail.com

http://orcid.org/0000-0002-1337-9828

Article Type: Research Article

https://doi.org/10.34234/ded.597237

Received Date: 20.07 .2019

Accepted Date: 24.12 .2019

Published Date: 25.06.2020

\section{Introduction}

Preschool period is the period in which the physical, emotional, social and mental development of the students is the fastest. Education in this period will also affects the child's personality development and learning process over the years significantly. Therefore, this education should be carried out in appropriate learning environments that will meet the basic needs of the child. Education should be planned considering the child's interest, needs and development status.

Effective and healthy acquisition of values to the individual is of great importance in terms of maintaining social integrity and peace and ensuring that so- 
cieties can live in safety. Values are believed to be a unifying factor for the individual and society and are used as criteria for desired behaviors. Many of the behaviors gained during the first phase of life will continue throughout the life of the child, the basic values of his family is important in terms of shaping the child's future. It is thought that the most effective institution that comes after the family is the school. For this reason, it is necessary to plan a good preschool period in which the behavior and habits of the child are shaped according to their value judgments and cultural structure of the society she/he lives in (Dereli İman, 2014, p. 262).

In this context, the development of feelings and behaviors that reflecting social value judgments such as love, respect, cooperation, responsibility, tolerance, cooperation, solidarity and sharing are among the main goals of preschool education. Music education is thought to be an effective tool in achieving these goals; it is thought that social, emotional, physical and mental development of the child will change positively with well planned music activities. In this general framework, it is aimed to determine the effect of values education through songs on children's awareness level in preschool period.

For this purpose, the following questions were sought:

1. Is there a significant difference between the pre-test results of the control and experimental groups?

2. Is there a significant difference between the pre-test and post-test scores of the control group?

3. Is there a significant difference between the pre-test and post-test scores of the experimental group?

4. Is there a significant difference between the post-test scores of the control and experimental groups?

5. Is there a significant difference between control and experimental group developments?

\section{Method}

In the research, pre-test post-test static group design was used. The study group of the research consists of two main classes, one of which is the experimental group and the other is the control group. There are 15 students each in the experimental and control groups formed the sample survey.

Song repertoire to be used in the application process of the research was de- 
termined within the framework of expert opinions; "Picture Cards Test" was developed by the researcher for the determined values and these picture cards were used as pre-test and post-test in order to determine the awareness levels of the students about these values.

The Picture Cards Test about values consists of pictures that reflect the values determined. During the application, picture cards were shown to the experimental and control group students respectively and they were asked what should be said and done about the situation they saw on the card. The answers given by the students were recorded and these records were watched by three field experts and scoring ranged from 1 to 5 .

Within the framework of the general purpose and main problem of the research, the data which are the sub-problems sought for answers were transferred to the computer and SPSS 23.0 package program was used for statistical solutions. For statistical significance, .05 significance level was selected. The pre-test and post-test scores of the experimental and control groups were obtained in the measurements carried out to determine the effect of music education performed on values education with the prepared song repertoire on the awareness levels of children. Mann-Whitney $U$ and Wilcoxon signed rank tests were applied to the data to analyze the differences between the groups in terms of pre-test scores, differences in terms of post-test scores, and the development between the pre-test and post-test.

\section{Findings}

According to Mann-Whitney U test results, there was no significant difference between pre-test score comparisons of experimental and control groups. A significant difference was found between the pre-test and post-test scores $(\mathrm{p}=.003)$ of the control group according to Wilcoxon signed rank test regarding the pretest and post-test scores of the control group. According to Wilcoxon signed rank test results between the pre-test and post-test scores of the experimental group, the pre-test scores of the experimental group increased significantly in the post-test $(\mathrm{p}=.001)$. According to Mann-Whitney $\mathrm{U}$ test results related to posttest scores of the experimental and control groups, the difference between the experimental and control groups in terms of cleanliness scores is not statistically significant. However, there was a significant difference in terms of friendship, trust and helpfulness scores. Although the difference in terms of cleaning scores of Mann-Whitney $U$ test results for comparison of experimental 
and control groups' developments (posttest-pretest score differences) was not statistically significant, it was found that there was a significant difference in friendship, trust and helpfulness development scores in experimental and control groups.

\section{Gonclusion and Discussion}

The following conclusions have been reached in line with the findings of this study conducted to determine whether there is any change in children's awareness of values through music activities performed with songs.

The values determined within the scope of the research were taught to the experimental group through songs containing these values. As a result of the analysis, no statistically significant difference was found between the pretest scores of the experimental and control groups. Wilcoxon signed rankings test which was conducted to determine whether there was a significant difference between the pre-test and post-test scores of the control group, showed that the control group had a significant improvement in friendship and helpfulness subscales and total scores $(\mathrm{p}<.05)$. When the pretest and post-test scores of the experimental group were analysed, it was observed that all sub-dimensions and total scores improved $(\mathrm{p}<.05)$.

According to the Mann Whitney $\mathrm{U}$ test which was conducted to determine whether there was a significant difference between the post-test scores of the experimental group and the control group, a significant difference was observed in favor of the experimental group $(\mathrm{p}<.05)$ in all subscales and total scores except the cleaning subscale. Although the experimental group scored higher in the cleanliness subscale, the difference was not significant.

In order to determine the difference between the groups, pre-test scores were removed from the post-test scores and the groups were compared in terms of difference scores. As a result of the analysis, it was seen that the difference in scores of the experimental group on all sub-dimensions and total scores were significantly higher $(\mathrm{p}<.05)$. Based on these analysis, it can be said that the development in the experimental group is much higher, although both groups showed improvement.

The education which will be realized in preschool period where learning takes place rapidly has great importance for children's cognitive, affective and dynamic development. Therefore, it is thought that music education which con- 
tribute to the development of both musical and other intelligence types, has an important place in preschool education. It is considered necessary that the music education to be realized in this period should be planned and programmed with effective applications according to the age, interest and needs of the child. Educational program that involve music education will not only contribute to the child's emotional, social and physical and mental development, it will also improve the growth of his/her aesthetic thought and appreciation and contribute to the formation of value judgments. Therefor, it is necessary to plan music education in pre-school education in accordance with the age level of the child, and to arrange the music education program by considering the method and scope required by music education in order to shape the future of children. 